\title{
Successive passaging through an apple host of six low-virulent Neonectria ditissima isolates increased virulence in one of them
}

\author{
Reiny W.A. Scheper ${ }^{*}$, Brent M. Fisher ${ }^{1}$, Joanna K. Bowen ${ }^{2}$, Nicholas T. Amponsah ${ }^{1,3}$ and \\ Duncan I. Hedderley ${ }^{3}$ \\ ${ }^{1}$ The New Zealand Institute for Plant and Food Research Ltd (PFR), Private Bag 1401, Havelock \\ North 4130, New Zealand \\ ${ }^{2}$ PFR, Private Bag 92 169, Mt. Albert, Auckland 1142, New Zealand \\ ${ }^{3}$ PFR, Batchelar Road, Palmerston North 4474, New Zealand \\ *Corresponding author: reiny.scheper@plantandfood.co.nz
}

\begin{abstract}
Neonectria ditissima is a serious pathogen of apple. Low-virulent cultures of this fungus have been isolated from cankers, but how and why low-virulent isolates can infect apple is unknown. Rasp wounds on 'Royal Gala' trees were inoculated with agar plugs from six low-virulent $N$. ditissima isolates in a glasshouse. Neonectria ditissima was re-isolated 10 weeks after inoculation. Agar plugs from the re-isolated cultures were used to inoculate 'Royal Gala' trees again. After the second re-isolation, conidial suspensions of the original cultures and the 2 × 6 re-isolates were used to determine the virulence on 'Royal Gala' compared with field-collected conidia. Three cultures did not cause any lesions; neither did their re-isolates. The re-isolates of two cultures did not differ in virulence compared with the originals. However, the virulence of one isolate increased with each re-isolation, with the second re-isolation causing significantly more lesions, lesion development occurring faster and the lesions being larger than those caused by the original isolate. Therefore, the virulence of $N$. ditissima isolates can change over time, with loss or gain possibly being attributed to epigenetic and/or genetic changes in the genome.
\end{abstract}

Keywords European canker, Neonectria galligena, Nectria galligena, pathogenicity, epigenetics, sub-culturing.

\section{INTRODUCTION}

Neonectria ditissima is a fungal pathogen that causes European canker on apple (Swinburne 1975; Weber 2014). Apple varieties differ in their susceptibility to canker but, to date, no immunity to European canker has been demonstrated (Garkava-Gustavsson et al. 2016; Gomez-Cortecero et al. 2016; Scheper et al. 2018). However, the identification of a resistance locus against this disease in Malus 'Robusta 5' (Bus et al. 2019) opens up the possibility of breeding highly tolerant or resistant cultivars through gene pyramiding with other resistances.
Conversely, the $N$. ditissima population varies in virulence on the apple host (Scheper et al. 2015) and conidial morphology (Scheper et al. 2014). Similarly, differential host-pathogen interactions in the Malus-N. ditissima pathosystem have been observed (Scheper et al. 2017).

The term virulence has a conflicting history among plant pathologists. Here we define virulence as the degree of damage caused to a host by a pathogen, assumed to be negatively correlated with host fitness (a quantitative property), while pathogenicity is defined as the qualitative capacity of a pathogen to infect and 
cause disease on a host (Sacristan \& GarciaArenal 2008).

The role of low-virulent $N$. ditissima isolates on apple is unknown, as are the underlying causes of low virulence. In a comparative genomics study of a high-virulent isolate (RS324p) and a lowvirulent isolate (RS305p) on apple, Deng et al. (2015) identified genomic differences between the two isolates, which may provide details on which genes are essential for virulence and pathogen fitness. This strategy has proved successful in revealing pathogenicity determinants in an increasing number of plant pathogens, by comparing genomes of either closely related species (Ma et al. 2010; Schirawski et al. 2010) or isolates within the same species (de Jonge et al. 2012; Schmidt et al. 2016). This can be extended to comparative population genomics and genomewide association studies, the latter applicable to sexually crossing species such as $N$. ditissima (Plissonneau et al. 2017). This approach assumes that the differences in virulence are caused by genomic sequence differences, as demonstrated in several fungal pathogens (Stergiopoulos \& de Wit 2009). However, virulence differences may also be caused by epigenetic regulation of gene expression. Epigenetic control relates to 'molecular processes around DNA that regulate genome activity independent of DNA sequences and are mitotically stable' (Dubey \& Jeon 2017). It is mediated by a range of mechanisms including modifications of DNA or histones (typically methylation or acetylation) that can lead to chromatin remodelling, and gene silencing and has been shown to play a role in virulence in fungal pathogens (Soyer et al. 2014; Dubey \& Jeon 2017). As epigenetic changes are dynamic and can be reversible, subject to environmental and/or physiological changes (Dubey \& Jeon 2017), a first step in identifying the cause of the low-virulence trait is to assess its stability when changing the environment of the isolate from growing on agar to growing inside a host plant.

In this study, the stability of the low-virulence trait was examined in six isolates by determining the effects on virulence of two successive passages through an apple host.

\section{MATERIALS AND METHODS Isolate selection}

Six low-virulent single-spore isolates of $N$. ditissima (Table 1) were selected based on previous screenings on leaf scars on potted 'Royal Gala' trees and rasp wounds on 'Braeburn' orchard trees in 2013 and 2014, respectively (unpublished data). The isolates tended to produce mainly one- and two-celled conidia in vitro (Scheper et al. 2014), while the percentage of multi-celled macro-conidia (i.e. $>2$ cells) ranged from $0 \%$ to $55 \%$ (Table 1 ). The percentage of inoculated wounds that developed canker symptoms (disease incidence) after inoculation with conidial suspensions is also shown in Table 1.

\section{Apple host and wound selection}

To facilitate infection with low-virulent isolates, the known susceptible apple accession 'Royal Gala' was chosen (Scheper et al. 2015; Amponsah et al. 2017; Scheper et al. 2018). Similarly, rasp wounds were used to optimise the chance of infection with low-virulent isolates, as larger wounds lead to shorter incubation periods and higher infection rates (Walter et al. 2016). In addition, agar plugs of isolates were used to increase the chance of infection, while conidial suspensions were used to determine virulence.

\section{Re-isolations after passages through the apple host}

A flow diagram outlining the experiment is shown in Figure 1.

\section{Infection with original isolates}

The isolates were grown for 2 weeks on potato dextrose agar (PDA, Merck) containing ampicillin $(50 \mu \mathrm{g} / \mathrm{mL})$ and streptomycin $(100 \mu \mathrm{g} /$ $\mathrm{mL}$ ). In June 2016, the central leader of 21 potted 1-year-old 'Royal Gala' trees on 'M9' rootstocks in a glasshouse were wounded;10 rasp wounds (4 $\mathrm{mm})$ per tree. An agar plug $(5 \times 5 \mathrm{~mm})$ was placed face-down on each wound and held in place with Glad $^{\circledast}$ wrap, which was removed after 24 hours. Each isolate was used to inoculate three trees ( 30 wounds per isolate). Three negative control trees 
Table 1 Low-virulent isolates of Neonectria ditissima collected in New Zealand, the percentage of conidia classified as macro-conidia (i.e. $>2$ cells) they produced in vitro, and the percentage of wounds with canker symptoms (disease incidence) on 'Royal Gala' leaf scars and 'Braeburn' rasp wounds after inoculation with conidial suspensions in 2013 and 2014, respectively. Isolates that were derived from a single conidium have a " $c$ " after their number, isolates derived from a single ascospore have a " $\mathrm{p}$ " after their number. A number after the " $c$ " or " $p$ " indicates that several single-spore isolates were derived from the same sporodochium or perithecium, respectively.

\begin{tabular}{lllrrr}
\hline \multirow{2}{*}{ Isolate } & $\begin{array}{l}\text { Location and year of } \\
\text { collection }\end{array}$ & Host variety & \begin{tabular}{c} 
Macro- \\
conidia \\
\cline { 5 - 6 }
\end{tabular} & & \multicolumn{2}{c}{ Disease incidence (\%) } \\
\cline { 5 - 6 } & & apple & 12 & 3 & 22 \\
ICMP14098 & Auckland, before 2006 & 'Royal Gala' & 'Braeburn' \\
RS305p & Lower Moutere, Nelson, 2009 & 'Brookfield' & 1 & 0 & 0 \\
RS322p1 & Rukuhia, Waikato, 2009 & 'Braeburn' & 14 & 3 & 56 \\
RS370p4 & Oratia, Auckland, 2010 & apple & 0 & 10 & 0 \\
RS402p1 & Lower Moutere, Nelson, 2010 & 'Brookfield' & 25 & 7 & 6 \\
MW12c & Riwaka, Nelson, 2013 & 'Scilate' & 55 & 3 & - \\
\hline
\end{tabular}

RS, MW, personal collection of author (R Scheper)

ICMP, International Collection of Micro-organisms from Plants, Manaaki Whenua Landcare Research, Auckland, New Zealand, but in the personal collection of author (R Scheper) since 2006

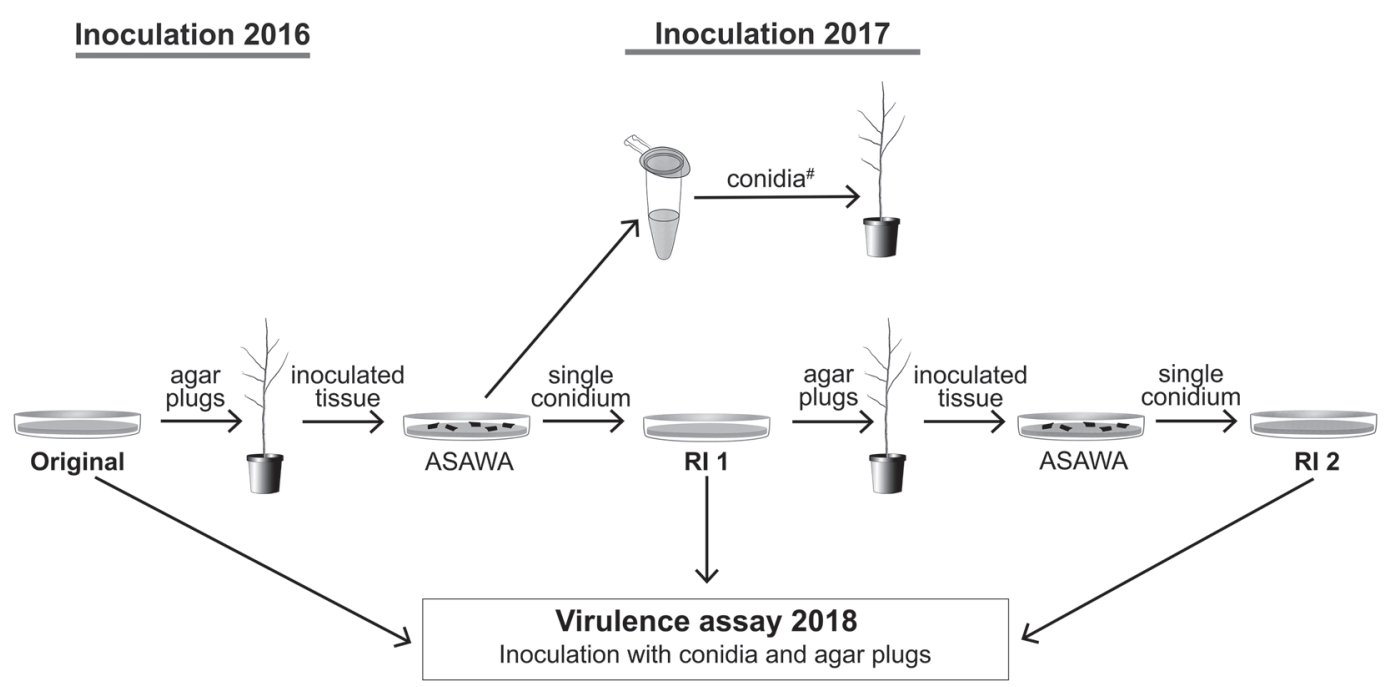

Figure 1 Flow diagram outlining the passages of each low-virulent Neonectria ditissma isolate through the 'Royal Gala' host, the first (RI1) and second (RI2) re-isolations and the virulence assay. Apple sap amended water agar (ASAWA) was used to re-isolate. \#Possibly heterogeneous mixtures of conidia, harvested from several inoculated wounds, were used to inoculate trees in 2017. 
were placed randomly among the inoculated trees and sterile agar plugs were placed on the wounds.

\section{First re-isolation}

Inoculated wounds were assessed for lesion development 5 and 10 weeks after inoculation (WAI). The fungi were re-isolated from the inoculated woody tissue from one tree per isolate, at 10 WAI. Ten $10-\mathrm{cm}$ sections, with the inoculated wound, or lesion, in the centre of each section, were surface sterilised in $70 \%$ ethanol for $30 \mathrm{~s}, 1 \%$ sodium hypochlorite for $1 \mathrm{~min}, 70 \%$ ethanol for $30 \mathrm{~s}$, then rinsed under tap water and air dried. The surface layer of the inoculated symptomless wound or lesion was excised aseptically and discarded. Small pieces $(2 \times 3$ $\mathrm{mm}$ ) from the wound or lesion edge were placed on apple sap-amended water agar (ASAWA, Amponsah et al. 2014), five pieces per plate. The plates were incubated on the laboratory bench, next to a window with no designated day/night regime, at an average temperature of $21^{\circ} \mathrm{C}$, and a range of $17.6-23^{\circ} \mathrm{C}$, for 11 days.

Conidia were harvested from uncontaminated $N$. ditissima mycelium on ASAWA plates by dislodging with 1-4 $\mathrm{mL}$ sterile distilled water (SDW). The spore concentration was determined using a haemocytometer (Hawksley counting chamber BN15 8TN, UK). Suspensions were frozen at $-20^{\circ} \mathrm{C}$ for 9 months until July 2017 (Scheper et al. 2015; Orchard et al. 2018).

In July 2017, the conidial suspensions of the reisolated isolates were defrosted, and $20 \mu \mathrm{L}$ of each suspension was spread onto antibiotic-amended PDA. One pure single-conidium $N$. ditissima isolate was obtained from each re-isolate. These isolates are identified by the designation "-RI1" after the isolate name.

\section{Infection with the first re-isolates}

One 'Royal Gala' tree per isolate was inoculated with agar plugs of the RI1 cultures, as described above, and sterile agar plugs were placed on the wounds of the negative control tree.

The remainder of the conidial suspensions were adjusted to $2 \times 10^{4}$ conidia/ $/ \mathrm{mL}$ and used to inoculate 'Royal Gala' trees, three trees per re- isolate, 10 rasp wounds per tree, $20 \mu \mathrm{L}$ per wound. Sterile distilled water droplets were pipetted onto the wounds of three negative control trees. The relative humidity in the glasshouse was increased to $100 \%$ for 2 days. The average temperature in the glasshouse during this time was $12^{\circ} \mathrm{C}$, with lows of $6^{\circ} \mathrm{C}$ and a high of $20^{\circ} \mathrm{C}$. After 2 days, the humidity was kept at $75 \%$. Inoculated wounds were assessed for lesion development 12, 14 and 16 WAI. Conidial germination rates were determined as described by Scheper et al. (2014).

\section{Second re-isolation}

Isolates were re-isolated for a second time, using only the trees that had been inoculated with agar plugs. If cankers with sporodochia were present, these conidia were suspended in SDW in October 2017. The spore concentration and the percentage of conidia that was multi-celled were determined before the suspensions were frozen at $-20^{\circ} \mathrm{C}$ for 4 months. In January 2018 , inoculated trees without sporodochia were cut into ten $10-\mathrm{cm}$ sections, with the inoculated wound or lesion in the centre, surface sterilised, and plated onto ASAWA as described above, except that ASAWA plates were incubated under continuous blacklight blue fluorescent light (providing near ultra violet (NUV) light, 350-390 nm Sylvania F15T8/BLB), at $18^{\circ} \mathrm{C}$ for 2 weeks. Conidia were harvested and stored as described above. A single-conidium isolate was prepared on antibiotic-amended PDA of all second re-isolates. These isolates are identified by the designation "-RI2" after the isolate name.

\section{Virulence assessment}

In April 2018, 2-week-old cultures of the six original isolates, the six first re-isolates (RI1) and the six second re-isolates (RI2) on antibiotic-amended PDA were sub-cultured onto Matsushima's medium (MM, Matsushima 1961) as adjusted by Dubin \& English (1974), and placed under NUV light at $20^{\circ} \mathrm{C}$ for 3 weeks. Conidia were harvested in SDW as described by Scheper et al. (2014). The conidial suspensions were adjusted to $2 \times 10^{4}$ conidia/ $\mathrm{mL}$ and the percentage of macro-conidia was 
determined as described above. In addition, the culture morphology on antibiotic-amended PDA was noted. The conidial germination rate was determined using suspensions with a higher concentration $\left(2 \times 10^{5}\right.$ conidia $\left./ \mathrm{mL}\right)$ to facilitate ease of counting. All conidial suspensions were frozen at $-20^{\circ} \mathrm{C}$ for 1 month.

In June 2018, 100 potted 1-year-old 'Royal Gala' trees on 'M9' were arranged in five blocks of 20 trees in a glasshouse, in a complete randomised block design. There were 20 treatments: the 18 isolates, a negative SDW control, and a positive control consisting of field inoculum of the same concentration. Field inoculum was made by transferring sporodochia from cankers collected from apple orchards in Motueka (Tasman), to SDW (Scheper et al. 2014; Scheper et al. 2015).

In blocks 1 to 4,10 rasp wounds per tree were inoculated with the defrosted conidial suspensions $\left(2 \times 10^{4}\right.$ conidia $\left./ \mathrm{mL}\right)$, one isolate per tree, $20 \mu \mathrm{L}$ per wound. The relative humidity in the glasshouse was increased to $100 \%$ for 2 days. The average temperature in the glasshouse during this time was $14^{\circ} \mathrm{C}$, with lows of $7^{\circ} \mathrm{C}$ and a high of $22^{\circ} \mathrm{C}$. After 2 days, the humidity was kept at $75 \%$. After inoculation, conidial germination rates were determined by spreading $100 \mu \mathrm{L}$ of each suspension (approximately 200 conidia) on antibiotic-amended PDA and counting the number of colonies after 9 days at $20^{\circ} \mathrm{C}$.

In block 5, 10 rasp wounds per tree (pseudoreplicates) were inoculated with agar plugs of the 18 isolates, as described above. Sterile agar plugs were placed on the wounds of the negative control tree, and the positive control tree was inoculated with agar on which field inoculum had been evenly spread and allowed to grow for 5 days at $20^{\circ} \mathrm{C}$.

Wounds were assessed weekly for canker symptoms 4-10 WAI, and then 14 and 20 WAI. The length of each lesion was measured in $\mathrm{mm}$.

\section{Statistical analyses}

Statistical differences between treatments in disease incidence (proportion of wounds that developed canker) of trees inoculated with conidial suspensions, 14 and 20 WAI, were determined by fitting a binomial generalized linear model with a logit link, and factors for block, isolate, re-isolation and isolate $\times$ reisolation interaction. 95\% confidence intervals for the proportions were calculated using the binomial distribution. The significance of differences between the proportions for pairs of isolates was assessed using a pairwise likelihood ratio test at $\alpha=0.05$ (no adjustment for multiple comparisons). Disease incidence in trees inoculated with agar plugs was analysed 9 and 20 WAI using the theoretical binomial variability.

The progress of disease incidence and of lesion length over time after inoculation with conidia were compared using area under the disease progress curve (AUDPC). For each tree, an area under the curve was calculated from the proportion of wounds with symptoms and the time in weeks. The AUDPC was analysed using analysis of variance (ANOVA), with tree as a block term, and isolate and re-isolation as treatment factors. The time from inoculation with conidia to the appearance of the first canker symptoms was also analysed using ANOVA. Bonferroniadjusted Least Significant Differences $(\alpha=0.05)$ were used to determine statistical differences in means between treatments.

The average lesion length 14 and 20 WAI, for each tree inoculated with conidia, was logtransformed to stabilise the variance and then analysed using linear mixed models. Trees with no lesions had a missing value for lesion size and were excluded from the analysis. Bonferroniadjusted Least Significant Differences $(\alpha=0.05)$ were used to determine statistical differences in mean lesion size between treatments. Lesion length in trees inoculated with agar plugs was analysed 20 WAI, using the isolate $\times$ re-isolation interaction as the residual.

The progress of lesion length over time after inoculation with conidia, was also compared using AUDPC, and was analysed using ANOVA, with tree as a block term, and isolate and reisolation as treatment factors.

Statistical analyses were carried out using GenStat software (version 17, 2014, VSNi Ltd, Hemel Hempstead, UK). 


\section{RESULTS}

\section{Re-isolations of the low virulent isolates}

Four of the six low-virulent isolates produced canker lesions after agar-plug inoculation of rasp wounds in 2016 (Table 2). All isolates were successfully re-isolated on ASAWA, resulting in conidial suspensions of each isolate. However, these suspensions also contained contaminants.

Inoculation with three of the six RI1 conidial suspensions resulted in lesions (Table 2). The conidial germination rate in all suspensions was low (2-20\%), but this did not affect infection, since inoculation with the two isolates with the lowest germination rates (2\% and $3 \%)$, ICMP14098-RI1 and RS322p1-RI1, respectively, resulted in high disease incidence $(45 \%$ and $83 \%$, respectively). Conidial suspensions that did not cause any lesions had a germination rate $>18 \%$.

Inoculation with agar plugs of the singleconidium RI1 isolates also resulted in lesions (Table 2) and, in October 2017, sporodochia were present in canker lesions of RS322p1-RI1 and RS370p4-RI1. Conidia of these sporodochia were harvested as the second re-isolates. The remaining four isolates were re-isolated on ASAWA. No N. ditissima was isolated from the uninoculated wounds of the negative control trees.

\section{Virulence assessment}

The percentage of macro-conidia in the conidial suspensions of the six low-virulent isolates and their re-isolates was low (0-8\%) compared with that in field conidia (65\%). The conidial germination rate of all defrosted suspensions (6-75\%) was high enough to cause infection of rasp wounds (Walter et al. 2016; Orchard et al. 2018) and in most suspensions it was similar to the rate from field inoculum (66\%, Table 3$)$. The original isolate RS322p1 did not produce any conidia. This isolate was only used for agar plug inoculations in this experiment.

The culture morphology of the isolates varied with regard to production of yellow/orange secondary metabolites, sectoring, wooliness and the presence of concentric rings. No differences were observed between the original isolates and the two re-isolates (RI1 and RI2) of RS305p, RS370p4 and RS402p1. However, the mycelium of ICMP14098 became more woolly with each successive re-isolation; the first and second reisolates of RS322p1 had sectoring mycelium, while the original isolate did not; and mycelia of MW12 and MW12c-RI1 were woolly, while that of MW12c-RI2 was not.

Isolates RS305p, RS402p1 and MW12c did not cause any lesions when inoculated with conidia, and neither did their re-isolates. Trees inoculated

Table 2 Percentage of rasp wounds with canker lesions (disease incidence) 10-14 weeks after inoculation (WAI) of 'Royal Gala' trees with agar plugs or conidial suspensions of either the original low-virulent Neonectria ditissima isolates or the first re-isolated isolates (RI1) from the 'Royal Gala' host of the isolates, assessed in 2016 and 2017.

\begin{tabular}{lccc}
\hline Isolate & \multicolumn{3}{c}{ Disease incidence (\%) } \\
\cline { 2 - 4 } & $\begin{array}{c}\text { Original isolate agar plug } \\
\text { 10 WAI (Aug. 2016) } \\
\mathrm{n}=30\end{array}$ & $\begin{array}{c}\text { RI isolate agar plug } \\
\text { 11 WAI (Oct. 2017) }\end{array}$ & $\begin{array}{c}\text { RI1 isolate conidia } \\
\text { 14 WA (Oct. 2017) } \\
\mathrm{n}=30\end{array}$ \\
\hline ICMP14098 & 60 & 100 & 45 \\
RS305p & 0 & 0 & 0 \\
RS322p1 & 33 & 100 & 83 \\
RS370p4 & 3 & 100 & 50 \\
RS402p1 & 10 & 0 & 0 \\
MW12c & 0 & 0 & 0 \\
\hline
\end{tabular}


Table 3 Characteristics of 18 conidial suspensions used to test the virulence of six low-virulent Neonectria ditissima isolates and their first (RI1) and second (RI2) re-isolates from infected 'Royal Gala' trees, compared with field-collected conidia, in 2018: the percentage of conidia that were multicelled macro-conidia, and the conidial germination rate determined on microscopy slides before the inoculum was stored at $-20^{\circ} \mathrm{C}$, and on antibiotic-amended potato dextrose agar (PDA) after inoculation of 'Royal Gala' trees.

\begin{tabular}{lccc}
\hline Isolate & Macro-conidia (\%) & \multicolumn{2}{c}{ Conidial germination rate (\%) } \\
\cline { 2 - 4 } ICMP14098 & 0 & Microscopy slides & PDA \\
ICMP14098-RI1 & 7 & 52 & 25 \\
ICMP14098-RI2 & 4 & 53 & 40 \\
RS305p & 0 & 39 & 7 \\
RS305p-RI1 & 0 & 75 & 20 \\
RS305p-RI2 & 0 & 31 & 10 \\
RS322p1 & - & - & 35 \\
RS322p1-RI1 & 1 & 26 & 50 \\
RS322p1-RI2 & 0 & 6 & 50 \\
RS370p4 & 0 & 54 & 18 \\
RS370p4-RI1 & 8 & 46 & 25 \\
RS370p4-RI2 & 0 & 72 & 25 \\
RS402p1 & 0 & 34 & 40 \\
RS402p1-RI1 & 8 & 67 & 30 \\
RS402p1-RI2 & 0 & 32 & 40 \\
MW12c & 0 & 37 & 40 \\
MW12c-RI1 & 0 & 68 & 35 \\
MW12c-RI2 & 0 & 74 & 30 \\
\hline Field conidia & 65 & 66 &
\end{tabular}

- This isolate did not produce conidia

with isolates ICMP14098 and RS322p1 had the highest disease incidence (Fig. 2). The isolate $\times$ re-isolation interaction was significant at $14 \mathrm{WAI}$ $(\mathrm{P}=0.028)$, but not at $20 \mathrm{WAI}$. At both assessment dates, ICMP14098-RI2 (53\% at 14 WAI and 63\% at $20 \mathrm{WAI}$ ) caused significantly higher incidence than the RI1 (20\%) and the original isolates (0\% at $14 \mathrm{WAI}$ and $8 \%$ at $20 \mathrm{WAI}, \mathrm{P}<0.001$ ), and at $14 \mathrm{WAI}$, the RI1 isolate caused significantly more disease than the original isolate $(\mathrm{P}<0.001)$. No significant differences were found between RS322p1-RI1 (30\%) and RS322p1-RI2 (25\%), or between the original, RI1 and RI2 versions of
RS370p4 (3\%, 3\% and 10\%, respectively). Field inoculum caused $100 \%$ incidence at $14 \mathrm{WAI}$, and no lesions were found in the negative control trees.

No significant differences in lesion length between isolates or re-isolations were observed at 14 or 20 WAI $(\mathrm{P}>0.79)$, but trees inoculated with field conidia had significantly longer lesions than trees inoculated with most isolates on both dates $(\mathrm{P}<0.001)$.

Using AUDPC of both disease incidence and lesion length, isolate ICMP14098 was the only isolate that significantly increased in 


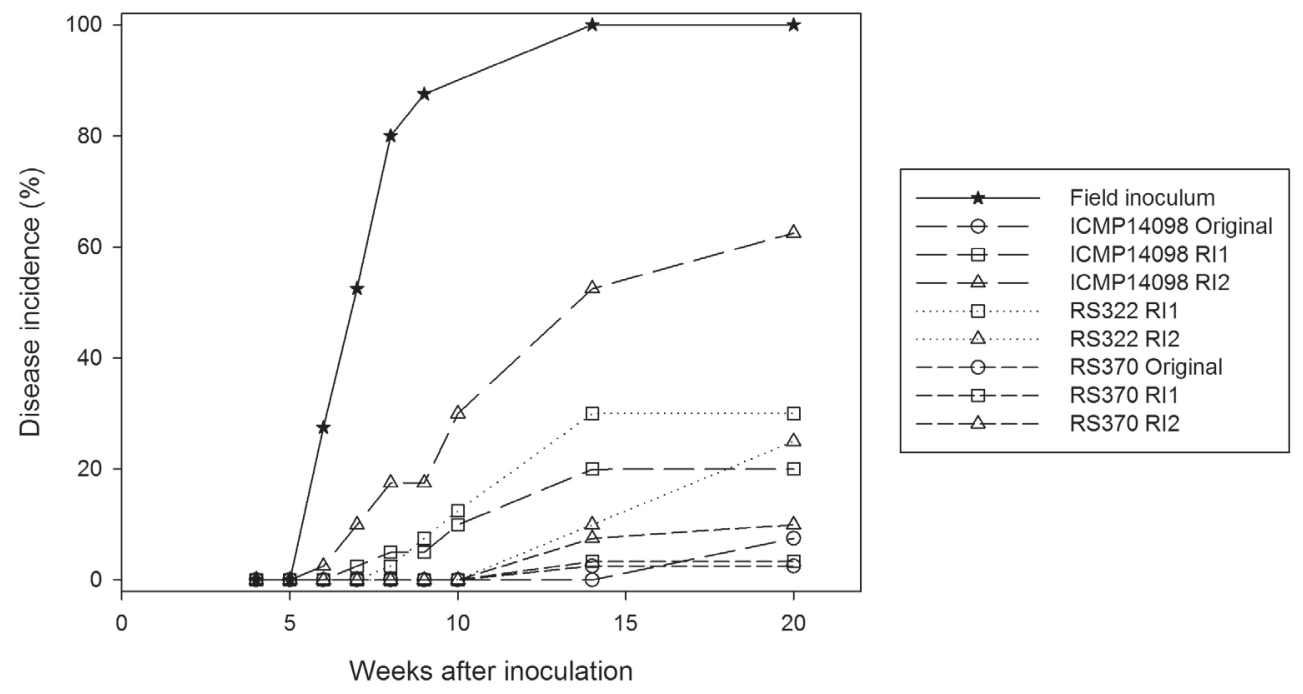

Figure 2 Mean European canker disease incidence (\%) of inoculated potted 'Royal Gala' trees over time, after inoculation with two low-virulent Neonectria ditissma isolates and their first (RI1) and second (RI2) re-isolations, as well as the re-isolates of a third low-virulent isolate, compared with disease incidence from field-collected conidia. The original isolate RS322p1 is not shown because it did not produce conidia.

virulence after two passages through the host (Table 4, $\mathrm{P}<0.001$ ). For isolate RS370p4, no significant differences between the original and the re-isolates were found, and in RS322p1, no significant differences between the re-isolates were found.

Isolate ICMP14098 also caused canker symptoms significantly faster after two passages through the host $(\mathrm{P}<0.001$, Table 4$)$, while there was no difference between RS370p4 and its two re-isolates, or the two re-isolates of RS322p1. Trees inoculated with field conidia developed symptoms before the other trees (6.5 WAI), however, not significantly faster than trees inoculated with some of the re-isolates (Table 4).

Most isolates caused canker symptoms when inoculated with agar plugs. Only MW12c-RI1 and RI2 did not produce any lesions, while only $10 \%$ of wounds inoculated with agar plugs of the original isolate MW12c developed a canker (Table 5). There were significant isolate effects
$(\mathrm{P}<0.001)$ based on pseudo-replicates, but no re-isolation effects $(\mathrm{P}=0.72)$. Every wound inoculated with agar plugs of ICMP14098, RS322p1 and RS370p4, and their re-isolates, as well as field inoculum grown on agar, developed into a canker (100\%). Agar plug inoculation with isolates RS305p and RS402p1 and their re-isolates resulted in an incidence of $10-50 \%$. Isolates that caused $100 \%$ incidence also had longer lesions than those with lower incidence, but field inoculum caused significantly longer lesions than any isolate tested $(\mathrm{P}<0.001)$, based on pseudo-replicates. There were no differences in lesion length between those produced by the original isolates and those by their re-isolates.

\section{DISCUSSION}

No lesions were found in the negative control trees and $N$. ditissima was not isolated from these trees, confirming that the trees used in this 
Table 4 Canker symptom development on potted 'Royal Gala' trees inoculated with conidia of six lowvirulent Neonectria ditissima isolates and their first (RI1) and second (RI2) re-isolates, compared with field-collected conidia, shown as area under the disease progress curve (AUDPC) of disease incidence and lesion length $(\mathrm{mm})$ until 20 weeks after inoculation, and the time (weeks) after inoculation when first canker symptoms were visible. The same letter indicates means which were not significantly different based on Bonferroni adjusted least significant difference (LSD).

\begin{tabular}{|c|c|c|c|}
\hline \multirow[t]{2}{*}{ Isolate } & \multicolumn{2}{|c|}{ Mean AUDPC } & \multirow{2}{*}{$\frac{\text { First symptoms }}{\text { (weeks after inoculation) }}$} \\
\hline & Disease incidence & Lesion length & \\
\hline Negative control & 0 & 0 & * \\
\hline Field conidia & $16.7 \mathrm{e}$ & $324 \mathrm{e}$ & $6.5 \mathrm{a}$ \\
\hline ICMP14098 & $0.2 \mathrm{a}$ & $14 \mathrm{a}$ & $20.5 \mathrm{~d}$ \\
\hline ICMP14098-RI1 & $2.0 \mathrm{a}$ & $73 \mathrm{ab}$ & $14.0 \mathrm{abcd}$ \\
\hline ICMP14098-RI2 & $5.7 \mathrm{~b}$ & $142 \mathrm{~b}$ & $9.3 \mathrm{ab}$ \\
\hline RS305p & 0 & 0 & * \\
\hline RS305p-RI1 & 0 & 0 & * \\
\hline RS305p-RI2 & 0 & 0 & * \\
\hline RS322p1 & - & - & - \\
\hline RS322p1-RI1 & $2.8 \mathrm{ab}$ & $124 \mathrm{ab}$ & $11.3 \mathrm{abc}$ \\
\hline RS322p1-RI2 & $1.3 \mathrm{a}$ & $56 \mathrm{ab}$ & $17.0 \mathrm{bcd}$ \\
\hline RS370p4 & $0.2 \mathrm{a}$ & $26 \mathrm{ab}$ & $19.3 \mathrm{~cd}$ \\
\hline RS370p4-RI1 & $0.3 \mathrm{a}$ & $24 \mathrm{ab}$ & $19.3 \mathrm{~d}$ \\
\hline RS370p4-RI2 & $0.7 \mathrm{a}$ & $26 \mathrm{ab}$ & $19.3 \mathrm{~d}$ \\
\hline RS402p1 & 0 & 0 & * \\
\hline RS402p1-RI1 & 0 & 0 & * \\
\hline RS402p1-RI2 & 0 & 0 & * \\
\hline MW 12c & 0 & 0 & * \\
\hline MW12c-RI1 & 0 & 0 & * \\
\hline MW12c-RI2 & 0 & 0 & * \\
\hline LSD & 2.7 & 102 & 6.2 \\
\hline
\end{tabular}

- This isolate did not produce conidia

* No lesions formed

experiment were canker-free. Therefore, the reisolated cultures were most likely derived from those originally used to inoculate the trees and not contaminants, as it is unlikely that all the trees would be contaminated with $N$. ditissima. However, that the re-isolates could have arisen from an introduced contaminant cannot be entirely ruled out. To confirm provenance of re-isolates, selected marker genes (Huang et al. 2019) or whole genome sequences (WGS) of the isolates and re-isolates could be compared (Malapi-Wight et al. 2016; Chalupowicz et al. 2019).

Field inoculum was significantly more virulent than all other isolates in every aspect: lesions appeared earlier, were longer, and the AUDPC of both disease incidence and lesion length were greater, confirming that all isolates used in this study, and their re-isolates, were low-virulent isolates. 
Table 5 Percentage of rasp wounds with canker lesions (disease incidence) 9 and 20 weeks after inoculation (WAI) of 'Royal Gala' trees with agar plugs of six low-virulent Neonectria ditissima isolates and their first (RI1) and second (RI2) re-isolates, compared with field-collected conidia, and their mean lesion length 20 WAI, assessed in 2018. Data are based on ten pseudo-replicates per isolate. The same letter indicates means which were not significantly different based on Bonferroni adjusted least significant difference (LSD).

\begin{tabular}{|c|c|c|c|}
\hline \multirow[t]{2}{*}{ Isolate } & \multicolumn{2}{|c|}{ Disease incidence (\%) } & \multirow{2}{*}{$\begin{array}{c}\text { Lesion length }(\mathrm{mm}) \\
20 \mathrm{WAI}\end{array}$} \\
\hline & 9 WAI & $20 \mathrm{WAI}$ & \\
\hline Negative control & $0 \mathrm{a}$ & $0 \mathrm{a}$ & * \\
\hline Field conidia & $100 \mathrm{~b}$ & $100 \mathrm{~b}$ & 37 \\
\hline ICMP14098 & $100 \mathrm{~b}$ & $100 \mathrm{~b}$ & 15 \\
\hline ICMP14098-RI1 & $100 \mathrm{~b}$ & $100 \mathrm{~b}$ & 19 \\
\hline ICMP14098-RI2 & $100 \mathrm{~b}$ & $100 \mathrm{~b}$ & 17 \\
\hline RS305p & $0 \mathrm{a}$ & $10 \mathrm{a}$ & 5 \\
\hline RS305p-RI1 & $30 \mathrm{ab}$ & $40 \mathrm{ab}$ & 9 \\
\hline RS305p-RI2 & $0 \mathrm{a}$ & $40 \mathrm{ab}$ & 7 \\
\hline RS322p1 & $100 \mathrm{~b}$ & $100 \mathrm{~b}$ & 27 \\
\hline RS322p1-RI1 & $100 \mathrm{~b}$ & $100 \mathrm{~b}$ & 19 \\
\hline RS322p1-RI2 & $100 \mathrm{~b}$ & $100 \mathrm{~b}$ & 28 \\
\hline RS370p4 & $100 \mathrm{~b}$ & $100 \mathrm{~b}$ & 24 \\
\hline RS370p4-RI1 & $100 \mathrm{~b}$ & $100 \mathrm{~b}$ & 25 \\
\hline RS370p4-RI2 & $100 \mathrm{~b}$ & $100 \mathrm{~b}$ & 24 \\
\hline RS402p1 & $10 \mathrm{a}$ & $50 \mathrm{ab}$ & 9 \\
\hline RS402p1-RI1 & $0 \mathrm{a}$ & $40 \mathrm{ab}$ & 9 \\
\hline RS402p1-RI2 & $0 \mathrm{a}$ & $20 \mathrm{a}$ & 6 \\
\hline MW12c & $0 \mathrm{a}$ & $10 \mathrm{a}$ & 6 \\
\hline MW12c-RI1 & $0 \mathrm{a}$ & $0 \mathrm{a}$ & * \\
\hline MW12c-RI2 & $0 \mathrm{a}$ & $0 \mathrm{a}$ & * \\
\hline
\end{tabular}

* No lesions formed

Isolates RS305p, RS402p1 and MW12c did not cause any lesions on the apple host following inoculation using conidia, and successive passages through the host did not change this. Similarly, the virulence in isolates RS322p1 and RS370p4 did not increase after passages through the host. These isolates did cause some lesions to develop after inoculation with conidia, but their low-virulence trait appeared to be stable. However, it cannot be ruled out that increased virulence might have been generated from these isolates if more re-isolated cultures had been carried forward after each passage through the host.

One low-virulent isolate (ICMP14098) increased in virulence after two successive passages through the host. In this isolate, the disease incidence and lesion length progress over time increased with each re-isolation, and canker symptoms developed faster with each successive re-isolation. Continued passaging may well further increase the virulence of ICMP14098RI2.

Increases in virulence have been observed 
when passaging fungal plant pathogens through both resistant and susceptible hosts (Wang et al. 2008; Alkher et al. 2009; Gao et al. 2012; Huang et al. 2019), although results from susceptible hosts are somewhat variable, with decreases also apparent (Huang et al. 2019). The mechanisms underlying these changes in virulence were not investigated explicitly during these studies. However, sequence variations (although without a correlation with virulence alterations; Wang et al. 2008), and moderated virulence gene expression (Huang et al. 2019) were both observed. Thus, in these pathosystems, alterations in virulence with passaging through the host may have been be due to sequence mutations. Alternatively, epigenetic modification may have played a role.

Assuming that virulence is the baseline, or original state of the pathogen, the low-virulence trait in isolate ICMP14098 appears to be reversible, with the degree of virulence depending on the environment encountered and, therefore, this may well be controlled epigenetically. Reversible epigenetic modifications modulating virulence have been observed following protracted in vitro culturing of Botrytis cinerea. In that study, loss of virulence, a common trait in many fungi during repeated sub-culturing, was accompanied by changes in global and local DNA methylation (Breen et al. 2016). Since isolate ICMP14098 has been in culture for many years, it is possible that the original virulence of this isolates was lost in a similar way. In $B$. cinerea, virulence could be reinstated by inoculating the plant host Arabidopsis thaliana, reversing the epigenetic modifications (Breen et al. 2016). A similar mechanism may be occurring in ICMP14098.

Of note is that $N$. ditissima demonstrates a high degree of phenotypic plasticity, as evidenced by morphological variability when culturing on artificial media, with some isolates readily forming sectors on PDA (unpublished data). This may suggest a level of epigenetic regulation of gene expression in $N$. ditissima, since sectorisation in the chestnut blight fungus Cryphonectria parasitica has been shown to be due to genome-wide hypomethylation, accompanied by down-regulation of genes encoding DNA methyltransferases (So et al. 2018). Epigenetic mechanisms may, therefore, be operating in $N$. ditissima to effect both in vitro and in planta plasticity.

To determine whether the increased virulence in isolate ICMP14098 following passaging through the host was due to genomic mutations or epigenetic modifications, the whole-genome sequences of the original isolate and its re-isolates will be compared (Deng et al. 2015) to identify any causative genetic mutations. Additionally, signatures of epigenetic modification can be analysed by, for example, bisulfite sequencing to identify DNA methylation status (Kurdyukov \& Bullock 2016). Similarly, these techniques can be used to establish the mechanisms underlying the stable low-virulence trait by comparison with isolates of higher virulence. The control of virulence may well prove to be highly complex, incorporating both sequence alterations and epigenetic modifications to effect a nuanced interaction with the host, thus, comparative genomics and epigenetic analyses may both be required to enable identification of virulence determinants in $N$. ditissima.

The percentage of macro-conidia in the conidial suspensions of the six low-virulent isolates and their re-isolates was low $(0-8 \%)$ compared with that in field conidia (65\%). However, this percentage was not always the same over time. For example, isolate MW12c was known to produce a high percentage of macroconidia in 2013 (55\%), but produced no macroconidia in 2018. Successive passages through the apple host, did not increase the percentage of macro-conidia in any of the isolates. Since the virulence of isolate ICMP14098 did increase with successive re-isolations, virulence and percentage macro-conidia do not appear to be linked in that isolate.

\section{CONCLUSIONS}

Successive passaging through apple hosts did not increase the virulence of $N$. ditissima isolates that failed to cause any disease after inoculation with conidia. Similarly, two of the three low-virulent isolates that caused some disease did not become 
more virulent after re-isolations from the host. The low-virulence trait appeared to be stable in those isolates.

One isolate (ICMP14098), which caused low levels of disease, increased in virulence with each successive passage through the host. In this isolate, the disease incidence and lesion length increased significantly over time after two successive re-isolations, and canker symptoms developed significantly faster. Assuming that virulence is the original state of the pathogen, the low-virulence trait in this isolate appears to be reversible.

Different mechanisms may be responsible for low virulence in $N$. ditissima, including possible genomic sequence or epigenetic changes that may or may not be reversible.

\section{ACKNOWLEDGEMENTS}

This work was funded by The New Zealand Institute for Plant and Food Research Limited. We thank Tony Corbett for making the flow diagram and Dr Vincent Bus, Dr Monika Walter (PFR) and Rachel Kilmister (New Zealand Apples \& Pears Inc.) for helpful comments on the manuscript draft.

\section{REFERENCES}

Alkher H, El Hadrami A, Rashid KY, Adam LR, Daayf F 2009. Pathogenic variation of Verticillium dahliae after serial passages through potato and sunflower. Canadian Journal of Plant Pathology 31: 427-438.

Amponsah NT, Walter M, Scheper RWA 2014. Agar media for isolation of Neonectria ditissima from symptomatic and asymptomatic apple tissues and production of infective conidia. New Zealand Plant Protection 67: 116-122.

Amponsah NT, Scheper RWA, Fisher B, Walter M, Smits JM, Jesson LK 2017. The effect of wood age on infection by Neonectria ditissima through artificial wounds on different of apple cultivars. New Zealand Plant Protection 70: 97-105.

Breen J, Mur L, Sivakumaran A, Akinyemi A, Wilkinson M, Lopez CMR 2016. Botrytis cinerea loss and restoration of virulence during in vitro culture follows flux in global DNA methylation. bioRxiv: 059477.

Bus VGM, Scheper RWA, Walter M, Campbell RE, Kitson B, Turner L, Fisher BM, Johnston SL, Wu C, Deng CH, Singla G, Bowatte D, Jesson LK, Hedderley DI, Voltz RK, Chagné D, Gardiner SE 2019. Genetic mapping of the European canker (Neonectria ditissima) resistance locus Rnd1 from Malus 'Robusta 5'. Tree Genetics \& Genomes 15, e25.

Chalupowicz L, Dombrovsky A, Gaba V, Luria N, Reuven M, Beerman A, Lachman O, Dror O, Nissan G, Manulis-Sasson S 2019. Diagnosis of plant diseases using the Nanopore sequencing platform. Plant Pathology 68: 229-238.

de Jonge $\mathrm{R}$, van Esse HP, Maruthachalam K, Bolton MD, Santhanam P, Saber MK, Zhang Z, Usami T, Lievens B, Subbarao KV, Thomma BPHJ 2012. Tomato immune receptor $V e 1$ recognizes effector of multiple fungal pathogens uncovered by genome and RNA sequencing. Proceedings of the National Academy of Sciences of the United States of America 109: 5110-5115.

Deng CH, Scheper RWA, Thrimawithana AH, Bowen JK 2015. Draft genome sequences of two isolates of the plant-pathogenic fungus Neonectria ditissima that differ in virulence. Genome Announcements 3: e01348-01315.

Dubey A, Jeon J 2017. Epigenetic regulation of development and pathogenesis in fungal plant pathogens. Molecular Plant Pathology 18: 887 -898.

Dubin HJ, English H 1974. Factors affecting apple leaf scar infection by Nectria galligena conidia. Phytopathology 64: 1201-1203.

Gao S, Liu T, Li Y, Wu Q, Fu K, Chen J 2012. Understanding resistant germplasm-induced virulence variation through analysis of proteomics and suppression subtractive hybridization in a maize pathogen Curvularia lunata. Proteomics 12: 3524 -3535.

Garkava-Gustavsson L, Ghasemkhani M, Zborowska A, Englund JE, Lateur M, Van de Weg E 2016. Approaches for evaluation 
of resistance to European canker (Neonectria ditissima) in apple. Acta Horticulturae 1127: 75-81.

Gomez-Cortecero A, Saville RJ, Scheper RWA, Bowen JK, De Medeiros HA, Kingsnorth J, Xu XM, Harrison RJ 2016. Variation in host and pathogen in the Neonectria/Malus interaction; toward an understanding of the genetic basis of resistance to European canker. Frontiers in Plant Science 7: 1365.

Huang X, Sun M, Lu X, Li S 2019. Serial passage through resistant and susceptible cucumber cultivars affects the virulence of Fusarium oxysporum f. sp. cucumerinum. Microbiologyopen 8, e00641.

Kurdyukov S, Bullock M 2016. DNA methylation analysis: choosing the right method. Biology 5, E3.

Ma L-J, van der Does HC, Borkovich KA, Coleman JJ, Daboussi M-J, Di Pietro A, Dufresne M, Freitag M, Grabherr M, Henrissat B, Houterman PM, Kang S, Shim W-B, Woloshuk C, Xie X, Xu J-R, Antoniw J, Baker SE, Bluhm BH, Breakspear A, Brown DW, Butchko RAE, Chapman S, Coulson R, Coutinho PM, Danchin EGJ, Diener A, Gale LR, Gardiner DM, Goff S, Hammond-Kosack KE, Hilburn K, Hua-Van A, Jonkers W, Kazan K, Kodira CD, Koehrsen M, Kumar L, Lee Y-H, Li L, Manners JM, Miranda-Saavedra D, Mukherjee M, Park G, Park J, Park S-Y, Proctor RH, Regev A, Carmen Ruiz-Roldan M, Sain D, Sakthikumar S, Sykes S, Schwartz DC, Turgeon BG, Wapinski I, Yoder O, Young S, Zeng Q, Zhou S, Galagan J, Cuomo CA, Kistler HC, Rep M 2010. Comparative genomics reveals mobile pathogenicity chromosomes in Fusarium. Nature 464: 367373.

Malapi-Wight M, Salgado-Salazar C, Demers JE, Clement DL, Rane KK, Crouch JA 2016. Sarcococca blight: use of whole-genome sequencing for fungal plant disease diagnosis. Plant Disease 100: 1093-1100.

Matsushima T 1961. A new medium for identification of hyphomycetes. Transactions of the Mycological Society of Japan 2: 118-120.
Orchard S, Campbell RE, Turner L, Butler RC, Curnow T, Patrick E, Walter M 2018. Longterm deep-freeze storage of Neonectria ditissima conidium suspensions does not reduce their ability to infect apple trees. New Zealand Plant Protection 71: 158-165.

Plissonneau C, Benevenuto J, Mohd-Assaad N, Fouche S, Hartmann FE, Croll D 2017. Using population and comparative genomics to understand the genetic basis of effectordriven fungal pathogen evolution. Frontiers in Plant Science 8, 00119.

Sacristan S, Garcia-Arenal F 2008. The evolution of virulence and pathogenicity in plant pathogen populations. Molecular Plant Pathology 9: 369-384.

Scheper RW, Fisher BM, Taylor T, Hedderley DI 2018. Detached shoot treatments cannot replace whole-tree assays when phenotyping for apple resistance to Neonectria ditissima. New Zealand Plant Protection 71: 151-157.

Scheper RWA, Fisher BM, Amponsah NT, Walter M 2014. Effect of culture medium, light and air circulation on sporulation of Neonectria ditissima. New Zealand Plant Protection 67: 123-132.

Scheper RWA, Frijters L, Fisher BM, Hedderley DI 2015. Effect of freezing of Neonectria ditissima inoculum on its pathogenicity. New Zealand Plant Protection 68: 257-263.

Scheper RWA, Smits JM, Fisher BM, Amponsah NT, Gubellini G, Jesson LK, Bus VGM 2017. Differential host-pathogen interactions of Malus and Neonectria ditissima. Science Protecting Plant Health, Brisbane, Australia. 26-28 September 2017. Abstract 142: 161.

Schirawski J, Mannhaupt G, Muench K, Brefort T, Schipper K, Doehlemann G, Di Stasio M, Roessel N, Mendoza-Mendoza A, Pester D, Mueller O, Winterberg B, Meyer E, Ghareeb $\mathrm{H}$, Wollenberg T, Muensterkoetter M, Wong P, Walter M, Stukenbrock E, Gueldener U, Kahmann R 2010. Pathogenicity determinants in smut fungi revealed by genome comparison. Science 330: 1546-1548. Schmidt SM, Lukasiewicz J, Farrer R, van Dam P, Bertoldo C, Rep M 2016. Comparative 
genomics of Fusarium oxysporum f. sp. melonis reveals the secreted protein recognized by the Fom-2 resistance gene in melon. New Phytologist 209: 307-318.

So K-K, Ko Y-H, Chun J, Bal J, Jeon J, Kim J-M, Choi J, Lee Y-H, Huh JH, Kim D-H 2018. Global DNA methylation in the chestnut blight fungus Cryphonectria parasitica and genome-wide changes in DNA methylation accompanied with sectorization. Frontiers in Plant Science 9, 00103.

Soyer JL, El Ghalid M, Glaser N, Ollivier B, Linglin J, Grandaubert J, Balesdent $\mathrm{M}-\mathrm{H}$, Connolly LR, Freitag M, Rouxel T, Fudal I 2014. Epigenetic control of effector gene expression in the plant pathogenic fungus Leptosphaeria maculans. Plos Genetics 10: e1004227.

Stergiopoulos I, de Wit PJGM 2009. Fungal effector proteins. Annual Review of Phytopathology 47: 233-263.

Swinburne TR 1975. European canker of apple (Nectria galligena). Review of Plant Pathology 54: 787-799.

Walter M, Roy S, Fisher BM, Mackle L, Amponsah NT, Curnow T, Campbell RE, Braun P, Reineke A, Scheper RWA 2016. How many conidia are required for wound infection by Neonectria ditissima? New Zealand Plant Protection 69: 238-245.

Wang B, Brubaker CL, Tate W, Woods MJ, Burdon JJ 2008. Evolution of virulence in Fusarium oxysporum f. sp. vasinfectum using serial passage assays through susceptible cotton. Phytopathology 98: 296-303.

Weber RWS 2014. Biology and control of the apple canker fungus Neonectria ditissima (syn. N. galligena) from a northwestern European perspective. Erwerbs-Obstbau 56: 95-107. 